\title{
ILCEA
}

Revue de l'Institut des langues et cultures

d'Europe, Amérique, Afrique, Asie et Australie

$26 \mid 2016$

Mémoire, vérité et justice en Uruguay

\section{La trasmisión del pasado traumático. Enseñanza de la dictadura y debate social en Uruguay}

Passing on the Traumatic Past. Teaching about Dictatorship and Social Debate in Uruguay

Transmettre le passé traumatique. Enseignement de la dictature et débat social en Uruguay

\section{Carlos Demasi}

\section{OpenEdition}

\section{Journals}

Edición electrónica

URL: http://journals.openedition.org/ilcea/3959

DOI: 10.4000/ilcea.3959

ISSN: 2101-0609

Editor

UGA Éditions/Université Grenoble Alpes

Edición impresa

ISBN: 978-2-84310-334-6

ISSN: 1639-6073

Referencia electrónica

Carlos Demasi, «La trasmisión del pasado traumático. Enseñanza de la dictadura y debate social en Uruguay », ILCEA [En línea], 26 | 2016, Publicado el 07 julio 2016, consultado el 21 abril 2019. URL http://journals.openedition.org/ilcea/3959; DOI : 10.4000/ilcea.3959

Este documento fue generado automáticamente el 21 abril 2019.

(C) ILCEA 


\title{
La trasmisión del pasado traumático. Enseñanza de la dictadura y debate social en Uruguay
}

\author{
Passing on the Traumatic Past. Teaching about Dictatorship and Social Debate \\ in Uruguay \\ Transmettre le passé traumatique. Enseignement de la dictature et débat social \\ en Uruguay
}

Carlos Demasi

1 En el año 2005 se produjo un cambio radical en las políticas estatales sobre el pasado reciente en Uruguay: muchos reclamos largamente demorados sobre las violaciones a los derechos humanos en la dictadura se pusieron en marcha: se activaron procesos judiciales a perpetradores, se inició la arqueología en los cuarteles, se abrieron archivos oficiales. La iniciativa de enseñar la historia de la dictadura formó parte de este impulso de autoafirmación social y su efecto se sumó al conjunto, generando expectativas y debates en la sociedad uruguaya.

2 Sin embargo, al cabo del tiempo el entusiasmo que despertó este giro dejó paso a cierto grado de decepción. En los sectores más activos de la sociedad se han manifestado actitudes de desaliento y de irritación al ver la lenidad con la que ha actuado la Justicia y los mensajes contradictorios que ha enviado a la sociedad, sumado a la idea de que también ésta ha reaccionado de forma débil y contradictoria. $\mathrm{Y}$ así como la expectativa por la enseñanza se sumaba al optimismo del comienzo, igualmente ahora se ve envuelta en el cuestionamiento a la eficacia de esas políticas. Al cabo de diez años de experiencias, parece oportuno reflexionar sobre estas resistencias sociales (que no solamente involucran a la enseñanza de la dictadura), y cúales podrían ser las futuras vías de acción. 


\section{Enseñar la historia de la dictadura: un proyecto cuestionado}

3 En muchos países, la enseñanza del pasado reciente aparece como un reclamo formulado por la sociedad, con una fundamentación que suena muy sólida y persuasiva. Si la función del sistema educativo es enseñar, ¿qué argumento puede oponerse a la demanda de aprender los hechos de la historia más reciente? Por otra parte, en una época en la que se acostumbra descargar sobre la educación la solución de todas las demandas sociales, desde la accidentalidad en el tránsito hasta las adicciones, ¿el reclamo de enseñar esa parte de la historia no sumaría el apoyo inmediato de aquellos que ven como natural que la educación se ocupe de proponer soluciones a toda dimensión de la realidad que la sociedad percibe como problemática? A esto puede agregarse otra consideración: ya que existe en el currículo una asignatura denominada «Historia» que se ocupa específicamente de la tarea de trasmitir el pasado, ¿no sería sencillo satisfacer la demanda social agregando un capítulo más al listado de temas a tratar en los cursos?

4 Estas consideraciones que parecen anunciar que la tarea de incorporar el pasado reciente a los contenidos de la enseñanza formal sería un simple paso burocrático, se ven desmentidas por las persistentes dificultades que el proyecto encontró cada vez que se intentó ponerlo en práctica. Esta ha sido la experiencia en el Uruguay donde las iniciativas para impulsar la enseñanza de la dictadura que gobernó el país entre 1973 y 1985, surgidas desde diferentes sectores sociales y políticos, chocaron con resistencias persistentes y siempre renovadas. Tanta persistencia parece apoyarse en razones que van más allá de la mala voluntad de algún jerarca o la oposición circunstancial de algunos sectores o de grupos que consideran que conviene dejar atrás ese pasado. Si estos fueran los motivos, podríamos suponer que quedarían atrás con el paso del tiempo, pero como veremos más adelante, la denominación «pasado reciente» ya resulta inadecuada cuando hablamos de episodios, como el golpe de Estado, ocurridos hace casi medio siglo. Recuérdese que desde marzo de 1985, es decir durante más de treinta años, se han sucedido con regularidad gobiernos constitucionales surgidos de elecciones que no han sido cuestionadas, es decir que no parece que sea efecto de la perduración de los sectores dominantes durante el gobierno militar.

5 También es llamativo el cambio de actitud del gobierno en 2005, que se explica por varias causas. Luego de múltiples demandas de la sociedad civil que habían sido desatendidas por los gobiernos, este giro tiene como antecedentes inmediatos la demanda del poeta argentino Juan Gelman, que a fines de 1999 hizo público el reclamo que le había formulado al Presidente uruguayo Julio M. ${ }^{a}$ Sanguinetti. Gelman tenía indicios de que su nuera desaparecida, que al tiempo de su detención cursaba los últimos meses de embarazo, había sido trasladada al Uruguay y que su hijo había sido apropiado por los perpetradores. Al principio el Dr. Sanguinetti se mostró sensible al reclamo pero luego paralizó las investigaciones. Cuando Gelman hizo pública su denuncia, Sanguinetti respondió que no había habido casos de apropiación de niños en la dictadura uruguaya, un discurso negacionista que ya había utilizado durante su primera presidencia (1985-1990) cuando, ya en democracia, se formularon los primeros reclamos de investigaciones sobre el paradero de los desaparecidos.

El segundo mandato presidencial de Sanguinetti terminó en medio del pedido de múltiples personalidades internacionales que le solicitaban que investigara la denuncia. 
Su sucesor, el Dr. Jorge Batlle, perteneciente al mismo sector político, no estaba dispuesto a hacerse cargo de un problema de su antecesor y pocas semanas después de asumir oficializó en una conferencia de prensa que Gelman tenía una nieta que vivía en Montevideo en el seno de una familia que la había criado desde muy pequeña. El anuncio del Dr. Batlle clausuró la búsqueda de Gelman pero reabrió un tema mucho más amplio, el de las investigaciones sobre el destino de los desaparecidos y sobre las violaciones a los DD. HH. cometidas durante la dictadura: era evidente la falsedad de la explicación oficial, que el mismo Dr. Sanguinetti había contribuido a elaborar, que decía que los desaparecidos uruguayos eran producto de la "pérdida de los puntos de referencia» (Allier Montaño, 2010: 118) en la lucha antisubversiva y que no había casos de niños secuestrados. Presionado por las circunstancias, en 2001 el Dr. Batlle decidió crear una «Comisión para la Paz» que se encargaría de cerrar el tema. Luego de dos años de actuaciones la Comisión divulgó su Informe Final donde confirmaban 26 denuncias y formulaban algunas sugerencias y recomendaciones. El 16 de abril de 2003 el gobierno decretó que las Conclusiones del Informe constituían la «verdad oficial» sobre el punto (Decreto del 16/04/2003) ${ }^{1}$. Las limitadas atribuciones de la Comisión (autorizada, según el Decreto $n .^{\circ} 858 / 2000$, a «recibir, analizar, clasificar y recopilar información sobre las desapariciones forzadas», una lista en la que no aparece el verbo «investigar») $)^{2}$ no daba posibilidades de clausurar legítimamente el tema. Por el contrario, y pese a sus limitaciones, el Informe incorporaba una novedad radical: reconocía oficialmente la existencia de casos de desaparición forzada en Uruguay que mostraban la aplicación de una política sistemática, y que el Estado era el responsable por esas desapariciones; por tanto, correspondía que proporcionara una respuesta a las demandas de los familiares y de las organizaciones sociales. Ante este reconocimiento, los reclamos continuaron.

7 En 2005 asumió un nuevo gobierno, presidido por el Dr. Tabaré Vázquez. Se trataba de un cambio relevante en la historia uruguaya: era la primera vez que ganaba las elecciones el «Frente Amplio», una coalición política creada en 1971, y el primer caso en la historia en el que el triunfador de las elecciones (y además, por mayoría absoluta) no era uno de los partidos tradicionales «Nacional» $\mathrm{y}$ «Colorado». Los militantes de esa fuerza política eran los que más habían sufrido la represión en tiempos de la dictadura; en su campaña electoral el Dr. Vázquez había prometido que ingresarían arqueólogos a los cuarteles a buscar los restos de desaparecidos, algo que en ese momento parecía una promesa de difícil cumplimiento. Luisa Cuesta, un referente de la lucha de las madres de los desaparecidos, en una entrevista realizada en febrero de 2004 todavía creía que los militares nunca permitirían el ingreso de los investigadores a los cuarteles (Demasi \& Yaffé, 2005: 99). Sin embargo, el nuevo presidente cumplió su palabra y durante 2005, en medio de gran expectativa social y rumores de «malestar en las Fuerzas Armadas» los arqueólogos comenzaron su trabajo. Durante varios meses las búsquedas fueron infructuosas y la presión política se estaba haciendo sentir, hasta que sobre fines del año se encontraron en dos establecimientos militares los restos de dos personas.

8 El hallazgo conmocionó la opinión pública: representaba el final de un relato largamente defendido que afirmaba que no había desaparecidos ni enterramientos en cuarteles y dejaba en claro la omisión del Estado en el cumplimiento de sus mínimos deberes de garante de los derechos ciudadanos. Fue en el contexto de las búsquedas de los arqueólogos forenses y reforzadas por las preguntas que los estudiantes formulaban en las aulas, que se puso en marcha una de las «Sugerencias generales» del Informe de la Comisión para la Paz: la de incluir el estudio de la dictadura en los programas de 
enseñanza (Informe final, § 81b). De esta forma terminaba de removerse el estancamiento generado por la ratificación plebiscitaria de la Ley de Caducidad, ocurrida en 1989 cuando terminaba la primera presidencia del Dr. Sanguinetti. Pasados más de 15 años de la instalación de aquel statu quo, la enseñanza de la dictadura dejaba de ser una práctica en los límites, subrepticia y siempre bajo amenaza, y salía a la luz pública, promovida y alentada (es decir, legitimada) por el poder político.

\section{El valor social del debate}

Este repaso, tal vez minucioso, de los acontecimientos que llevaron a que se reactivara el debate social sobre la dictadura, parece mostrar que el bloqueo no deriva de la mala voluntad de algunos funcionarios o de las ideas propias de algún partido político circunstancialmente en el poder, sino que atraviesan toda la sociedad uruguaya, perduraron más allá de los mandatos presidenciales y superan la rotación democrática de los partidos. Como resultado de este cambio impulsado desde el gobierno se reactivaron las causas judiciales por delitos no comprendidos en la Ley de Caducidad (como resultado, dos ex presidentes, un ministro y varios oficiales retirados fueron condenados a penas de prisión) y acompañando la demanda por la aplicación del art. $4^{\circ}$ de la Ley de Caducidad que obliga al Poder Ejecutivo a investigar las denuncias de violaciones a los derechos humanos en la dictadura ${ }^{3}$, se designó un equipo de historiadores coordinado por el Dr. Álvaro Rico, que por primera vez fue encargado de investigar las denuncias. Fue entonces que por primera vez se pudo acceder a algunos archivos oficiales con documentación que hasta entonces se había mantenido celosamente oculta. Los resultados de la investigación (dos series de volúmenes en los que se describen las prácticas del terrorismo de Estado en sus diversas formas y en particular las denuncias de desaparecidos) (Rico, 2007, 2008) colocaron a la «historia de la dictadura» en un status similar al de la historia de cualquier otro período histórico, al diversificar sus fuentes y utilizar documentación oficial. En lo que se refiere a la enseñanza, también permite apreciar el peso de una decisión tomada por la autoridad educativa que contaba con el apoyo del gobierno: esta vez la propuesta iba decididamente en el sentido contrario de lo que había sido la actitud predominante por lo menos desde que terminó el mandato del prof. Juan E. Pivel Devoto, el primero de los Directores de Enseñanza Pública designado por la democracia en 1985 y también el primero que promovió la inclusión de la dictadura en los contenidos de la enseñanza oficial.

Como era previsible, estas acciones generaron fuerte debate público y permitieron la expresión de las más diversas posiciones. Como un primer aspecto en un balance positivo, la apertura del debate abrió espacio para la difusión de experiencias hasta entonces poco conocidas, como era el caso de las «mujeres rehenes» de la dictadura) (Ruiz \& Sanseviero, 2011) e igualmente estimuló investigaciones y artículos periodísticos sobre el tema donde se mezclaron desde aportes importantes hasta chicanas político-partidarias. Luego el tema salió de la agenda y fue sustituido por otros. El debate se apagó siguiendo una pauta de actitudes bastante típica: denuncias primero y escándalo después, para luego languidecer hasta su desaparición. Frente a ese resultado, lo primero que cabe preguntarse es si se justificaba promover una operación de política educativa tan fuerte como la que se llevó adelante. Claramente la respuesta es afirmativa, pero más allá de ese acuerdo, conviene subrayar algunos aspectos que definen la importancia de la discusión. En primer término hay que recordar que la acción estatal es la señal central del proceso 
de legitimación social, en último término siempre es el Estado el que define la agenda de temas «legítimos» y el que habilita o no el acceso de las demandas sociales al espacio de los debates públicos.

11 En este caso además, el gesto de la autoridad educativa permitió romper el muro de silencio y de represión que encerraba el tema, no solamente en cuanto a la enseñanza sino también en aspectos que involucran a la investigación; pero estos aspectos generaron más controversia. Aquí también, la idea de dejar estos hechos en el olvido tenía sus partidarios que argumentaban que eran hechos ya pasados y que lo mejor era dejar que la información quedara en manos de las familias. Ante una situación parecida Adorno señalaba el valor del debate sobre el pasado, contradiciendo a aquellos que pensaban que lo mejor era «no remover recuerdos», y afirmaba que

[...] parece más bien que la elevación a consciencia nunca tiene consecuencias tan funestas como la inconsciencia, la semiconsciencia y la preconsciencia. Lo realmente importante aquí es cómo se representa y actualiza el pasado; si la cosa se queda al nivel del nuevo reproche o hace frente a la consternación mediante la capacidad y la fuerza de llegar a comprender incluso lo incomprensible. (1998: 27)

La operación implicó poner en palabras los argumentos y exponer los fundamentos de las posiciones encontradas, pero tuvo también sus efectos perversos, ya que en algunos casos los involucrados recuperaban los antiguos antagonismos. La descripción de los acontecimientos re-presentaba los aspectos argumentales y emocionales propios del pasado, lo que terminaba replanteando las posturas más radicales. En este escenario, un mecanismo de «reconocimiento de errores» aparecía como una traición a su propio pasado y una autocrítica despertaba poco eco. Pero si bien estos aspectos pueden fundamentar un juicio un poco frustrante del proceso de debate, debemos tener presente que su sola existencia permitió legitimar la práctica del diálogo y de poner en palabras los episodios traumáticos del pasado. Pero también Adorno advertía algunos riesgos en estas instancias de debate social:

[...] en cualquier caso, los intentos de enfrentarse subjetivamente al potencial objetivo del mal, elevándolo a consciencia, no deberían darse por satisfechos con legitimaciones que no desenmascararan la gravedad de aquello contra lo que hay que proceder. Alusiones [a los méritos de las víctimas] apenas ayudan nada, por ciertas que puedan ser, sino que saben a propaganda. $Y$ la propaganda es, en cuanto manipulación racional de lo irracional, patrimonio del totalitarismo. [...] Si éste es tan difícil de vencer, es porque la economía psíquica de innumerables personas, ha precisado, y presumiblemente aún sigue precisando hoy, de él. Lo que se hace propagandísticamente permanece siempre en la ambigüedad. (1998: 27-28)

La manera de pensar de quienes comparten los fundamentos de las políticas represivas del pasado difícilmente pueda verse afectada por el intercambio de opiniones. Las diferentes estrategias que se manifestaron (la defensa radical de las actitudes asumidas en el pasado, los intentos de incluir el propio caso personal dentro de un contexto justificatorio, o argumentar que «la dictadura no había sido tan mala» (versión local de la estrategia defensiva que menciona Adorno en su conferencia), o incluso el silencio, no diferían mucho en lo substancial. Y es así que pudo verse una paradójica coincidencia: que tanto desde los perpetradores como desde las víctimas surgieron voces que argumentaban que la enseñanza institucional del golpe de Estado y la dictadura eran inoportunas y que para realizar una tarea de ese tipo había que esperar a que todos los protagonistas murieran. En ese contexto comenzó a ponerse en práctica el proyecto de incorporar la etapa de la dictadura en el marco de la enseñanza formal. 


\section{El choque con las tradiciones históricas} profunda en la sociedad uruguaya, que es conveniente analizar. ¿Por qué resulta tan difícil asumir el debate y la difusión de los acontecimientos represivos de la dictadura, en el marco del sistema educativo? En este caso no se trata de la existencia de complicidad social retrospectiva, real o supuesta: dentro de las limitadas posibilidades de la época, los uruguayos manifestaron mayoritariamente su rechazo a la dictadura en 1980 cuando el régimen convocó a un plebiscito procurando su consolidación institucional. Las razones de esa displicencia deben buscarse más allá de las dinámicas del sistema educativo, y parecen vincularse a la adhesión social que concitan tres tradiciones que son muy fuertes: la Historia nacional como narrativa, el pasado como práctica social, y la función social encomendada a la educación.

\section{La dictadura en el relato de la Historia}

En Uruguay la construcción de un relato histórico fue el resultado de una laboriosa tarea emprendida en el último tercio del siglo xIx y que recién a mediados del siglo xx alcanzó un consenso social apreciable. El resultado no es fruto de una reconstrucción científica sino una elaboración que construye performativamente la identidad de la comunidad identificada como «la nación». En ella aparecen ejemplos de las virtudes del colectivo (no tanto las del pasado sino las del presente en que se construye el relato) y describe aquellos rasgos con los que «los uruguayos» quieren verse identificados. En este contexto, la enseñanza de la dictadura, sus antecedentes y sus secuelas choca con la construcción de la nación y su tradición, encargada de la transmisión de ejemplos virtuosos.

Para el caso uruguayo, el "gran relato» del pasado describía una historia de perfeccionamiento ciudadano: el pasaje progresivo de la primitiva sociedad «bárbara» donde los conflictos se resolvían por medio de la guerra civil, a una comunidad «civilizada» donde las relaciones sociales se encuentran reguladas por la ley y donde el voto es la forma legítima de arbitrar las discrepancias. Es ilustrativa la manera cómo el relato de la historia contribuyó a lograr este resultado: los partidos que en el siglo xx uruguayo predominaron electoralmente y compartieron el poder, se consideran herederos de los bandos que se enfrentaban en las guerras civiles en el siglo xIx. Pero, como ha dicho Ricœur, «Los mismos acontecimientos significan para unos la gloria, para otros la humillación. [...] Así es que se encuentran guardados, en los archivos de la memoria colectiva, heridas reales y simbólicas» (2000: 99). Cuando el relato de estos conflictos se formula a la vista del resultado final, se transforma en una justificación de los triunfadores, lo que en clave de construcción nacional significa que uno de los bandos poseía el secreto de la «verdad» que encerraba el futuro, mientras que el otro se debatía por hacer triunfar el error; pero una narrativa así construida no contribuiría a integrar la comunidad. La narrativa final distribuyó más equitativamente las demandas de modo tal que también el bando «derrotado» pudo ufanarse de haber contribuido a consolidar el orden democrático, y por esa vía participar en la construcción del presente. Este resultado es el producto de una operación historiográfica que merecería un análisis como el que dedicó Spivak a los estudios sobre subalternidad (Spivak, 1997), rastreando la 
estrategia que permite presentar como compatible lo que originalmente se formulaba como contradictorio.

Una ventaja que operó de manera muy relevante en el éxito de la estrategia de reconstrucción del pasado fue el paso del tiempo, pero no por su simple acumulación sino por su capacidad de transformar la realidad: cuando la historiografía presentó las guerras civiles del siglo xIx como la lucha entre formas complementarias de concebir la democracia política, las circunstancias políticas habían cambiado tan radicalmente que no sobrevivía el interés por replantear debates que habían quedado sepultados en el pasado. Pero a 30 años de terminado el episodio autoritario, todavía la realidad social impide distribuir de manera «equitativa» los perfiles virtuosos del presente entre víctimas y victimarios. En este contexto, la pretensión de incorporar el pasado traumático al conjunto de la experiencia de la comunidad cuestiona con fuerza su existencia, la inclusión de la dictadura desajusta ese relato y de allí que haya quienes propongan, como señalaba Renan en su célebre conferencia, el olvido como mecanismo de reconstrucción de la nación.

La imposición social del olvido o esperar el simple paso del tiempo no parecen buenos recursos para superar las resistencias y extraer de la experiencia social de la dictadura una enseñanza positiva para las generaciones futuras. Para eso es necesario imaginar una redistribución general de los sentidos del pasado que abra espacio a una cuota de «maldad» en el espíritu de la comunidad a la que también se debe construir una historia. Esto implica una de dos posibilidades: o bien estuvo siempre presente en la nación (y entonces es tarea de la historia ponerlo a la vista), o bien es el producto original de una circunstancia histórica concreta y allí corresponde entonces a la historia describir cuáles son los elementos que configuraron esa combinación perversa. Se trata de compromisos epistemológicos diferentes en uno y otro caso: en uno predomina el carácter modélico del pasado, mientras que en el otro se introduce una visión crítica.

Pero la utilidad de la trasmisión del pasado ha derivado de su capacidad para extraer ejemplos positivos o guías para la acción, partiendo de la premisa que el sujeto nacional es siempre virtuoso. En esa dimensión la experiencia histórica sigue funcionando como un continuo donde el pasado sirve de guía y enseñanza para el presente. A pesar de la crítica de Koselleck, este uso de la historia sigue siendo el de «magistra vitae» (1993: 41-66) y todavía no existe una lectura posible del pasado que supere el carácter ejemplar que le adjudica la tradición. Con diversos formatos comunicacionales, la historia argumenta que su contenido es digno de conocerse en cuanto nos propone «aprender del pasado»; y ese aprendizaje siempre se plantea en términos de valores o de ejemplos. ¿Cómo señalar elementos para reconocer en el presente el espacio de maldad que existe en la nación, sin introducir en ella una dimensión irreductible de conflicto?

\section{Cambio de sentidos y cambio de la práctica social}

Puede admitirse que, en último término, aprendemos de nuestras tradiciones. Es decir, incorporamos los nuevos conocimientos en el marco y con los sentidos que nos proporciona una tradición ya determinada. La historia, en cuanto práctica social, participa de esa relación y establece un vínculo muy denso entre el pasado, que es su objeto de estudio, y el presente, que le proporciona su marco y sus sentidos. La socialización implica el proceso de transformación del individuo en sujeto social, lo que supone la incorporación de todo aquello que integra el sentido común societal. Dentro de 
ese conjunto está incorporada una visión del pasado que no tiene puntos conflictivos con la ideología social y que "ya está allí» cuando comienza la tarea de investigación del historiador. Como dice Habermas,

[...] a la comprensión del historiador le ha tomado ya siempre la delantera un contexto de tradición que determina la situación hermenéutica de partida y, por tanto, también la comprensión del historiador. Pero precisamente por ello, a través de la comprensión histórica se efectúa a la vez la prosecución de la tradición que el historiador hace suya. Desde este punto de vista el acontecer histórico cobra un núcleo de validez que antecede a toda reflexión. (1997: 43)

Esto supone que cualquier descubrimiento o reinterpretación novedosa que formulen los historiadores tiene grandes posibilidades de resultar chocante para el colectivo social, que reacciona manifestando su rechazo. Cuando la reconstrucción historiográfica involucra pautas para la acción, naturalmente el rechazo es más fuerte y en esa dimensión se incluyen muchos de los resultados de las investigaciones que manejan archivos de la dictadura: la cuota de maldad que revelan los resultados impulsa el sentido común que la pretensión de considerar tales episodios como «pasados».

La Historia no es la obra de una persona aislada en la soledad de su escritorio sino una construcción social y en su construcción la sociedad tiene un papel activo y no meramente pasivo, siempre actúa seleccionando lo que acepta y lo que rechaza y descarta. La construcción del sentido común en la sociedad es una tarea continua en la que participa toda la sociedad y que no puede ser monopolizada por ningún sector. En esta tarea permanente de elaboración la sociedad nunca se reproduce a sí misma, el sentido común se modifica por las sucesivas acciones que se procesan en la sociedad. Por lo tanto cada reefectuación supone una variación. La dinámica de este proceso supone que el cambio en el sentido común de la sociedad no puede ser orientado en una dirección determinada, no es rápido ni simultáneo en todas sus dimensiones. Como el cambio no es homogéneo, la modificación de la percepción social del pasado tampoco lo es: pueden producirse fracturas que modifican rápidamente el sentido de los hechos y que hacen que generaciones diferentes que coexisten en determinado presente histórico, tengan visiones muy distintas sobre los mismos acontecimientos. En esa diferencia se incluye también un debate sobre actitudes políticas en el pasado y su reflejo en el presente. En esta dimensión, necesariamente el debate se transforma en político y de esa forma interpela a todas las posiciones, tanto a los conservadores como a la izquierda. Aquí el debate involucró la memoria, no como fuente de información sino como espacio de poder: el control del pasado es un arma política de primera importancia, especialmente en un país donde ha predominado una mirada tradicionalizante que localiza en la historia una clave para la comprensión del presente.

La dimensión de poder social que supone el dominio de la memoria atribuye al historiador el poder de producir convicción con la sola enunciación de un relato sobre el pasado, olvidando la complejidad de la construcción del sentido común en la sociedad. No cualquier versión del pasado será aceptada, por prestigioso que sea el historiador que la enuncie, porque la ideología no es producto de un sector social, se trata de un proceso donde, de formas diversas, participa toda la sociedad. Como señalábamos al principio citando a Adorno, la discusión de estos relatos (aun aquellos supuestamente «neutrales») facilitan el discernimiento de las posiciones y los cuestionamientos al sentido común predominante, que es una construcción interesada. Este cambio generó reacciones y se multiplicaron las versiones del pasado en forma de testimonios, memorias, reconstrucciones históricas, etc. Toda esta diversidad tenía un valor muy desigual, pero el 
hecho de que tantos hayan sentido la necesidad de sistematizar y poner por escrito sus visiones del pasado, hace que éste salga del difuso consenso social y lo transforme en un contenido consciente. Como decía Adorno, esta variedad «nunca tiene consecuencias tan funestas como la inconsciencia» y aunque se tratara de una estrategia propagandística, eso no los excluye del espacio de ambigüedad de toda propaganda, que como tal puede ser objetada y confrontada.

Librada a su propio impulso, la idea predominante sobre qué fue la dictadura y cuáles fueron sus causas tiende a construir una visión homóloga a la que indica el sentido común de lo que es «ser uruguayo». El período de la dictadura entró muy rápido en lo que se ha llamada «la era del testigo» y para algunos resulta incomprensible que no se recurra simplemente a los «testigos de la época» (es decir, los portadores de la memoria) para la reconstrucción de la Historia. Las experiencias límite vividas por muchas de las víctimas (fugas, torturas, prisión prolongada en situaciones extremas, exilios, etc.) se transformaron rápidamente en objeto de interés público y muy pronto comenzaron a aparecer los testimonios y las reconstrucciones biográficas de las experiencias de dirigentes e integrantes de la guerrilla. De esta manera el pasado quedó configurado como un campo de sentido donde se enfrentan dos antagonistas, el MLN y los militares y en el que también los primeros, en cuanto resistentes y sobrevivientes, reclaman una porción de éxito. En esa configuración bipolar se pierde de vista el hecho de que no hay continuidad temporal ni causal entre la lucha contra la guerrilla (que efectivamente puede explicarse como un enfrentamiento entre dos fuerzas) y el golpe de Estado, un gesto en el que organizaciones sociales y políticas enfrentaron a las Fuerzas Armadas y un grupo de dirigentes civiles: para cuando se produjo este quiebre institucional, hacía casi un año que la guerrilla había sido desarticulada.

Por otra parte, un campo tan fuertemente polarizado ha servido de marco para el despliegue de la «teoría de los dos demonios» que pretende distribuir por igual la responsabilidad de la dictadura entre la guerrilla y las Fuerzas Armadas. Ya han sido explicadas las connotaciones ideológicas de este esquema explicativo y su utilidad para fundamentar la implantación de un orden conservador en la etapa pos-dictadura ${ }^{4}$, pero para el caso interesa subrayar que se trata de un recurso argumental que tiene fuerte consenso en los debates sociales, aunque sea muy escaso su fundamento a la luz de la investigación histórica. En esta configuración, los conflictos que dividieron la sociedad en el pasado encuentran una forma de permanecer en el presente y tienen la fuerza suficiente como para incidir en la conformación de la manera de pensar de toda la sociedad; pero también profundizan la confusión que existe entre la reconstrucción historiográfica del pasado y la representación de la memoria. Como ésta no es un equivalente de la historia ni actúa socialmente de la misma forma, difícilmente puedan coincidir en su relato aunque trabajen con elementos similares. La subjetividad elaborada y transmitida por la memoria puede servir como marco del relato elaborado por la historiografía, pero no puede sustituirse por él. La reconstrucción historiográfica de la dictadura entra en conflicto con la versión de los sobrevivientes, que no están en situación de aclarar críticamente su propia participación.

En estos casos el manejo del testimonio por el historiador involucra tanto la aplicación de las herramientas críticas de su práctica como su compromiso ético con la situación que describe, lo que no deja de afectar el abordaje de su objeto (Ricœur, 2000: 337). Reconstruir el contexto en el que se vivieron experiencias límite en términos que no coinciden con las memorias de los testigos, involucra la perspectiva de un desencuentro y 
las cuestiones de identidad que se ven involucradas son mucho más interpelantes que las discrepancias de estas reconstrucciones con la ideología social.

\section{La enseñanza del trauma: aprender del pasado como experiencia negativa}

Cuando ya está promediando la segunda década del siglo, los conflictos que desembocaron en la dictadura, tan vivos aún para algunos que fueron sus protagonistas, están quedando progresivamente en el pasado. El paso del tiempo está desdibujando el sentido de aquellos gestos y frases que encerraban la clave de la comprensión en la época. Pero así como la sociedad está apartándose gradualmente de la realidad de la dictadura, ese fenómeno también se manifiesta en el sistema educativo. Los jóvenes que hoy están en el sistema recibiendo clases sobre la dictadura, nacieron ya en el siglo xxi y no tienen ninguna experiencia directa de esos acontecimientos. Para los menores de 30 años, el episodio más traumático de la historia del país seguramente no sea el quiebre institucional de 1973 sino el impacto de la crisis económica de 2002 y el momento de máxima exaltación emocional no se identifique con el restablecimiento de la Constitución luego de la dictadura (una jornada que se vivió como una fiesta popular) sino con el desempeño de la selección uruguaya de fútbol en el Mundial de Sudáfrica. Este cambio de perspectiva es simplemente resultado del renuevo generacional y no caben los juicios de valor respecto de los episodios involucrados, son datos a tener en cuenta porque configuran realidades nuevas.

En el sistema educativo uruguayo este cambio de referencias abre la posibilidad de liberar la práctica educativa de un problema que involucra aspectos fundacionales del sistema. En sus orígenes, la educación pública debió intervenir en una sociedad atravesada por conflictos fratricidas donde la guerra ocupaba casi todo el espacio del pasado. Para cumplir sus objetivos, el aula debía ser «un campo neutral hasta donde no llegara el incendio de las pasiones políticas y en cuyo tranquilo recinto no resonase en eco ronco de las animosidades y los odios que naturalmente genera la guerra civil» (Varela, 1910: 198) y este objetivo se cumplió exitosamente. Como forma de conservar el «tranquilo recinto» la evolución posterior instauró el principio de laicidad, que en su versión uruguaya involucra más a la «neutralidad» político-partidaria que a la enseñanza religiosa: supone que el docente debe presentar con honestidad e imparcialidad los contenidos políticamente polémicos. Por lo tanto, el sesgo partidista es un pecado que debe evitarse.

La brecha generacional enfría el impacto de los hechos y permite su análisis más sereno, así puede incorporarse el conflicto como contenido de enseñanza y utilizar su análisis como un procedimiento pedagógico. Cuando se trata de la trasmisión a los más jóvenes, implica sumergir el relato en la misma profundidad temporal que cualquier otro episodio del pasado. De esta manera puede ganarse en riqueza analítica lo que se pierde en involucramiento emocional, un componente que no debe perderse por completo cuando están en juego la trasmisión de compromisos éticos.

El efecto desdramatizador de este distanciamiento puede resultar positivo en un espacio como la enseñanza de la dictadura donde las sensibilidades parecen haber permanecido tan alerta, y por esa vía parece posible llegar a la naturalización de su enseñanza, pero eso también aleja emocionalmente a los jóvenes. El compromiso emocional que interpele a los estudiantes es un componente importante cuando se trata de sensibilizar sobre la gravedad de las violaciones a los derechos humanos y sobre el peligro de las alteraciones 
del orden institucional. De lo contrario se corre el riesgo de que se entienda que los derechos humanos solo se violaron en la dictadura y por esa vía se anule la sensibilidad para las situaciones perpetradas en el presente, una consecuencia que es importante evitar.

\section{La experiencia de la dictadura como problema inconcluso}

31 Aunque el tema sigue generando rispideces, la dictadura se ha incorporado a la realidad social. No cabe duda que la imagen de la dictadura ha cambiado en el correr de esta década y no solamente por el efecto de su inclusión en la enseñanza: se ha configurado una nueva realidad que volvió posible lo que hasta poco tiempo antes era impensable. La arqueología en los cuarteles, los procesamientos a militares involucrados en las denuncias y la apertura de los archivos, dejaron a la vista otras dimensiones de la represión mientras inauguraban otras posibilidades de acción en la sociedad. Este conjunto de hechos contribuyeron a disipar uno de los fantasmas más permanentes de la posdictadura: la amenazante expectativa de una reacción militar que desembocara en otro golpe de Estado o en una situación de desobediencia castrense. Cuando se produjo el plebiscito de la Ley de Caducidad, en 1989, este había sido uno de los argumentos principales de los defensores de la ley; ahora, el ingreso de los arqueólogos a los cuarteles $\mathrm{y}$ de los generales a los juzgados penales fueron la imagen del sometimiento del poder militar a la autoridad civil.

Sin embargo, algunas situaciones hacen comprensible el malestar que manifiestan muchos juristas y militantes sociales. Puede haber cierta decepción frente a los resultados de las campañas arqueológicas en los predios militares, iniciadas con gran expectativa pero que en pocos casos lograron localizar restos de desaparecidos, o mucha perplejidad ante las contradictorias decisiones de la Suprema Corte de Justicia respecto a los delitos de lesa humanidad. Puede cundir el desánimo cuando el intento de introducir un artículo en la Constitución para anular la Ley de Caducidad en 2009 no alcanzó el número de votos necesario. Sin duda que a estos hechos pueden contraponerse otros: hay civiles y militares condenados por delitos de lesa humanidad (hasta 2007 no había habido ninguno), los pocos restos que se han encontrado han servido para desmantelar el negacionismo predominante desde 1985 y el hallazgo de los restos del maestro Julio Castro (asesinado de un disparo en la cabeza) también desmintió la idea de la dictadura benévola que sólo ocasionalmente había perdido los «puntos de referencia». Respecto de la actitud de la sociedad, hay que señalar como lo hace F. Lessa (2014), que dos de las organizaciones sociales más numerosas y activas, la central sindical y la Federación de estudiantes, continúan fuertemente comprometidas con el tema.

Si bien es cierto que podemos descubrir el efecto que las diversas líneas de acción han tenido sobre la sociedad, es mucho más difícil señalar cuál ha sido la incidencia de la enseñanza de la dictadura en el comportamiento social. Ya vimos que no hay una relación lineal entre una práctica educativa y su impacto social. Aprender en la enseñanza es distinto de aprender socialmente, los contenidos no son asimilados como simple resultado de la vida social sino que se trata de experiencias provocadas en un contexto de aprendizaje, es decir que les son impuestas a los alumnos. Si lo que pretendemos es que «aprendan de esa historia», tenemos que tener presente que se trata de un aprendizaje 
que va a contramano tanto de la tradición predominante en los contenidos impartidos hasta ese momento en el curso, como también de los intereses inmediatos de los jóvenes. Es claramente perceptible cómo estos contenidos involucran de manera diferente a los adultos y a los jóvenes: la re-creación de un enfrentamiento a cuatro décadas de ocurrido y que todavía aparece tan lleno de contenido para los protagonistas, pierde completamente su sentido para los jóvenes, al haber desaparecido el contexto que lo volvía comprensible. La insistencia puede generar hastío y rechazo en los jóvenes, precisamente los efectos contrarios a los buscados.

Igualmente persisten algunos peligros aún si se tienen presentes esos riesgos y se actúa en consecuencia. Lo que fácilmente puede resultar es la conclusión de que «la memoria» y «los derechos humanos» resulten aspectos que solo atañen a la dictadura, y que no involucran en nada las dimensiones cotidianas del presente. Si la experiencia social de la violación de los derechos humanos en la dictadura queda circunscripta en el tiempo y en el espacio, su valor se reduce a los recuerdos y las demandas de un grupo y dejan de interpelar a la sociedad en su conjunto. En ese caso la sociedad puede llegar a convivir con flagrantes violaciones a los derechos, sin percibir la continuidad de una situación que atraviesa las diferentes épocas sin transformarse en lo sustancial.

Esto no debe verse como un mensaje pesimista, toda práctica social cambia con el tiempo y una estrategia que pretenda enfrentar directamente a los problemas del pasado que no se han resuelto y que revise críticamente las experiencias que llevaron a la instalación de un episodio de autoritarismo, puede promover la consolidación de las tradiciones democráticas. Posiblemente para eso sea necesario modificar levemente el eje de la acción educativa, seleccionando con cuidado cuales son los episodios de la dictadura que interesa evocar para abrir espacio a la reflexión sobre las características del terrorismo de Estado y los medios para impedirlo en el futuro. De esta manera se puede integrar la defensa jurídica de la dignidad humana a las modalidades habituales de comportamiento de la sociedad, sin que aparezca exclusivamente como una secuela de los episodios ocurridos en el pasado.

Parece importante pensar que el mantenimiento de una actividad de difusión de los principios de los derechos humanos en la sociedad puede ser una línea de acción que desarrolle la sensibilidad ante las efectivas y actuales violaciones a la dignidad de las personas. Esto sería así el principal legado del autoritarismo a la sociedad: no la perduración de las prácticas autoritarias sino su extinción y la creación de una conciencia alerta a la vigencia de los derechos.

\section{BIBLIOGRAFÍA}

ADORNo Theodor (1998), «¿Qué significa superar el pasado?», T. Adorno, Educación para la emancipación, Madrid: Morata, 15-29.

ALLIER MONTAÑo Eugenia (2010), Batallas por la memoria: los usos políticos del pasado reciente en Uruguay, Montevideo: Trilce-IIS. 
COMISIÓN PARA LA PAZ (2003), Informe Final, Presidencia, Montevideo: IMPO. Disponible en < www.usip.org/sites/default/files/file/resources/collections/commissions/UruguayReport_Informal.pdf> [consultada el 08/03/2016].

Demasi Carlos (2004), «Un repaso a la teoría de los dos demonios», A. Marchesi, V. Markarian, A. Rico \& J. Yaffé (comps.), El presente de la dictadura, Montevideo: Trilce, 67-74.

DemASI Carlos \& YAFFÉ Jaime (coords.) (2005), Vivos los llevaron... Historia de la lucha de madres y familiares de detenidos desaparecidos (1976-2005), Montevideo: Trilce.

FRANCO Marina (2015), «La “teoría de los dos demonios” en la primera etapa de la posdictadura», C. Feld \& M. Franco (dirs.), Democracia, hora cero, Buenos Aires: FCE, 23-80.

HABERMAS Jürgen (1997), «¿Aprender de la historia?», J. Habermas, Más allá del Estado nacional, Madrid: Trotta, 39-48.

KOSELLECK Reinhardt (1993), «Historia Magistra Vitae. Sobre la disolución del topos en el horizonte de la agitada historia moderna», R. Koselleck, Futuro pasado. Para una semántica de los tiempos históricos, Barcelona-Buenos Aires: Paidos, 41-66.

LESSA Francesca (2014), ¿Justicia o impunidad? Cuentas pendientes en el Uruguay post-dictadura, Montevideo: Penguin-Sudamericana Uruguaya.

Rico Álvaro (2005), Como nos domina la clase gobernante, Montevideo: Trilce.

RICo Álvaro (coord.) (2007), Investigación histórica sobre detenidos desaparecidos, 5 tomos, Montevideo: Presidencia de la República, IMPO. Disponible en <http:// archivo.presidencia.gub.uy/_web/noticias/2007/06/2007060509.htm> [consultada el 05/03/2016].

RICo Álvaro (coord.) (2008), Investigación histórica sobre dictadura y terrorismo de Estado en Uruguay (1973-1985), 3 tomos, Montevideo: Universidad de la República, CEIU. Disponible en < www.geipar.udelar.edu.uy/alvaro-rico-coord-investigacion-historica-sobre-dictadura/> [consultada el 05/03/2016].

RicceUR Paul (2000), La mémoire, l'histoire, l'oubli, Paris: Seuil.

RuIZ Marisa \& SANSEVIERo Rafael (2011), Las Rehenas, Montevideo: Fin de Siglo.

SPIVAK Gayatri Chakravorty (1997), «Estudios de la subalternidad. Deconstruyendo la historiografía», S. Rivera Cusicanqui \& R. Barragán, Debates postcoloniales. Una introducción a los estudios de la subalternidad, La Paz, Bolivia: SEPHIS-Ediciones Aruwiyiri, 247-277.

VARELA José Pedro (1910), La legislación escolar, Montevideo: El Siglo Ilustrado.

\section{NOTAS}

1. «Se aceptan Conclusiones del Informe Final de la Comisión para la Paz», Decreto de 16 de abril de 2003. Disponible en <http://web.archive.org/web/20090627034654/http:// www.presidencia.gub.uy/decretos/2003041605.htm> [consultado el 08/03/2016].

2. Decreto . $^{\circ} 858 / 200$, Creación de la Comisión para la Paz, Presidencia de la República, 9 de agosto de 2000. Disponible en <http://web.archive.org/web/20090516232647/http:// www.presidencia.gub.uy/noticias/archivo/2000/agosto/2000080912.htm> [consultado el 08/03/2016]. 
3. Disponible en <https://parlamento.gub.uy/documentosyleyes/leyes? Ly_Nro=15848\&Searchtext=\&Ly_fechaDePromulgacion[min][date]=14-12-2015> [consultado el 03/03/2016].

4. La bibliografía al respecto es abundante. A título de ejemplos, para el caso uruguayo: Rico (2005) y Demasi (2004); para el caso argentino, Franco (2015).

\section{RESÚMENES}

Este artículo repasa el lento proceso de debate social sobre las violaciones a los DD. HH. en la dictadura uruguaya. Explora el impacto de esas violaciones como contenido de enseñanza en el sistema educativo y lo compara con la memoria de otras experiencias traumáticas, en busca de dar cuenta del retraso en la concepción de un programa educativo en la materia y también de avizorar posibles desarrollos futuros.

This paper reviews the slow process of social debate on Human Rights violations during the Uruguayan dictatorship period. It explores the impact of such violations as the content of teaching in the education system and it compares this case with other memories about traumatic experiences, in order to account for the former's constant postponement and also to envisage likely future developments.

Cet article revient sur le lent processus de débat social quant aux violations des droits de l'homme perpétrées pendant la dictature uruguayenne. Il explore l'impact de ces violations en tant que contenu d'enseignement dans le système éducatif en le comparant aux récits mémoriels relatifs à d'autres expériences traumatiques, afin de rendre compte du retard dans la conception d'un programme d'éducation en la matière et d'envisager des perspectives de développements futurs.

\section{ÍNDICE}

Mots-clés: Uruguay, dictature, droits de l'homme, mémoire sociale, enseignement

Keywords: Uruguay, dictatorship, human rights, social memory, teaching

Palabras claves: Uruguay, dictadura, DD. HH., memoria social, enseñanza

\section{AUTOR}

\section{CARLOS DEMASI}

Centro de Estudios Interdisciplinarios Uruguayos (FHCE-UDELAR) 